\title{
Ocular defects in infants of extremely low birth weight and low gestational age
}

\author{
Priscilla Burgess, Ann Johnson
}

\begin{abstract}
The eyes of 49 babies who weighed less than $1000 \mathrm{~g}$ at birth or who were born at or before 28 weeks gestation were examined at the age of 4 years. Twenty-one children were normal. The remaining 29 children (59\%) had ocular abnormalities which ranged from mild amblyopia to blindness from retinopathy of prematurity. The need to examine children at risk is stressed.
\end{abstract}

The recent increase in survival of babies of extremely low birth weight (ELBW), that is, weighing less than $1000 \mathrm{~g}$, and infants of low gestational age (28 weeks or less) has led to increasing concern about their long term outcome. Overall less than half of these babies survive,' though survival rates as high as $63 \%^{2}$ are achieved in some areas. A recent metaanalysis of a large number of follow-up studies of ELBW infants has shown that just over a third of all survivors (36\%) were impaired. ${ }^{3}$ Most of this impairment is of neurological origin - that is, cerebral palsy, sensory deficit, and learning difficulties. The most serious ocular defect in these babies is retinopathy of prematurity (ROP), and several studies have confirmed that the risk of ROP is inversely related to birth weight. ${ }^{4-6}$ In particular, cicatrical, binding ROP is more common in infants weighing under $1 \mathrm{~kg}$ at birth. ${ }^{57-9}$

The literature contains little information on the outcome of babies of low birth weight and low gestational age from the ophthalmological as distinct from a developmental standpoint. Saigal et $a l^{10}$ described the findings at the age of 2 years of a group of ELBW infants from a geographically defined region in Canada. She noted an overall incidence of ROP of $38 \%$. There were eight children with one or both eyes blind from ROP from a population of 110 survivors $(7 \%)$. Two children had reduced vision due to optic atrophy (2\%), 17 were myopic (16\%), 13 had strabismus $(12 \%)$, and one had nystagmus (1\%). Keith and Kitchen ${ }^{11}$ in a similar study noted ocular lesions in $33 \%$ of survivors: $10 \%$ had cicatricial ROP, $3 \%$ had optic atrophy, $17 \%$ had considerable refractive error, and $19 \%$ had squint. Hungerford $e t a l^{12}$ in a study of babies born before 33 weeks of gestation found ocular pathology in $15 \%$. The commonest problem was refractive error; $8 \%$ had ROP, and $5 \%$ had delayed visual maturation. Both these studies were hospital based and described survivors from one centre.

In 1984 a study was undertaken of all infants born to mothers resident in the Oxford Region and who weighed less than $1000 \mathrm{~g}$ at birth or who were born at or before 28 weeks' gestation. The eyes of $72 \%$ of this cohort of ELBW babies were also examined. The main purpose of this report is to give a detailed description of the ocular findings.

\section{Patients and methods}

Sixty-eight of 127 (54\%) babies born alive to mothers in the Oxford Region and who weighed less than $1000 \mathrm{~g}$ or who were born at of before 28 weeks' gestation survived to their fourth birthday. The eyes of 49 of the 68 survivors were examined during a two-year period from June 1987 to June 1989 . The mean age of the children ( 25 girls, 24 boys) at the time of visual assessment was 4 years 4 months (range 3 years 8 months to 4 years 11 months).

The ocular assessment consisted of the following: The parents were questioned about eye disease either in the child or in the family, with particular reference to strabismus and myopia. A detailed neonatal history was available from the hospital notes. The ocular motility was assessed, and examination included pursuit and saccadic eye movements, and a cover test for near and distance. Visual acuity was measured where possible with a linear Snellen chart or linear Sheridan Gardner or Kay pictures. In non-verbal children the ability to fix and follow small targets was assessed. We also undertook confrontation visual field tests using finger counting in the quadrants; TNO tests (named after authors Toegepast, Natuurwetenschappelijk, Onderzoek to measure stereopsis; Slit-lamp examination; and refraction and indirect ophthalmoscopy following the instillation of cyclopentolate $1 \%$.

Not all children were examined by an ophthalmologist as neonates. Whether or not such an examination was performed depended on the intensive care unit in which the child was treated.

\section{Results}

The ocular findings in 21 to 49 (43\%) children were normal. The remaining 28 children (59\%) were found to have a variety of ocular abnormalities (Table 1).

RETINOPATHY OF PREMATURITY

Two of $49(4 \%)$ children had severe cicatricial

Table 1 Ocular defects

\begin{tabular}{lcc}
\hline & $\begin{array}{l}\text { Number of } \\
\text { children }\end{array}$ & $\begin{array}{l}\text { Percentage of } \\
\text { children }\end{array}$ \\
\hline Retinopathy of prematurity & 2 & 4 \\
Strabismus & 12 & 25 \\
Myopia & 5 & 10 \\
Optic nerve head abnormalities & 5 & 10 \\
\hline
\end{tabular}


ROP. The first was born at 26 weeks' gestation and weighed $720 \mathrm{~g}$. She suffered from respiratory distress syndrome, was ventilated until the fifth day of life, and had supplemental oxygen in a headbox until the sixteenth day. She also had a patent ductus arteriosus which was treated with indomethacin. At 6 months of chronological age she was noted to have roving eye movements and was found to have bilateral closed funnel retinal detachments. At age 4 years she was blind in both eyes and entirely retarded, with a severe communication disorder.

The second child with severe cicatricial ROP was born at 24 weeks' gestation and weighed $632 \mathrm{~g}$. She was ventilated for six weeks and sustained an intraventricular haemorrhage. When assessed the right eye was normal, but the left was divergent and had an eccentric macula with a dragged disc and temporal vasculature. Interestingly this eye was highly hypermetropic and astigmatic. This child had made good developmental progress, and neither child with ROP had associated cerebral palsy.

Another child when seen during the neonatal period had acute ROP (grade 2 maximally) but was normal when seen at age 4 . A further child had mild mid peripheral retinal pigmentary speckling as her only abnormality at age 4 :

\section{STRABISMUS}

Twelve of $49(24 \%)$ children had strabismus (Table 2). Of the eight convergent cases, six were non-accommodative, one partially accommodative, and one infantile. There were four divergent squints, three constant and one intermittent.

Three children were myopic (range -2 to -8 dioptres). All three had a non-accommodative pattern esotropia.

Nine of the 12 squinting children had reduced acuity in one or both eyes. In six this was due to sensory deprivation, in three it was associated with myopia, one had hypoplastic discs, one had optic atrophy and one had ROP. Six of the children had neurological or behavioural problems. Four had cerebral palsy, one was developmentally delayed, and the sixth was hyperactive.

A further child not included above had a past history of strabismus but was not squinting when seen at 4 years. She also had no evidence of stereopsis.

Table 2 Associations found with strabismus

\begin{tabular}{lllll}
\hline & $\begin{array}{l}\text { Convergent } \\
\text { non } \\
\text { accommodative }\end{array}$ & $\begin{array}{l}\text { Convergent } \\
\text { partially } \\
\text { accommodative }\end{array}$ & $\begin{array}{l}\text { Convergent } \\
\text { infantile }\end{array}$ & Divergent \\
\hline Number & 6 & 1 & 1 & 4 \\
Myopia & 3 & 1 & & 3 \\
Amblyopia & 5 & 1 & 1 \\
Neurological defect & 5 & & & \\
\hline
\end{tabular}

Table 3 Optic nerve head abnormalities

\begin{tabular}{|c|c|c|c|c|}
\hline & $\begin{array}{l}\text { Number of } \\
\text { children }\end{array}$ & Bilateral & Unilateral & $\begin{array}{l}\text { Neurological } \\
\text { deficit }\end{array}$ \\
\hline Optic atrophy & 2 & 1 & 1 & 2 \\
\hline Optic nerve hypoplasia & 1 & 1 & & $\bar{l}$ \\
\hline Optic disc drusen & 1 & & 1 & \\
\hline Tilted discs & 1 & 1 & & \\
\hline
\end{tabular}

\section{OPTIC NERVE HEAD ABNORMALITES}

Five of $49(10 \%)$ children had either unilateral or bilateral abnormalities of the optic nerve head (Table 3). There were two children with optic atrophy. The first had unilateral involvement and a visual acuity of $6 / 18$ in the affected eye. The second with bilateral involvement was also cortically blind and could not fix or follow a target with either eye. Of the remaining three children one had bilateral optic nerve hypoplasia and very poor acuity in both eyes, another had a large irregularly shaped left optic disc probably due to buried drusen and a visual acuity of $6 / 12$ in the affected eye. The third had bilateral tilted discs with mild oblique astigmatism but normal visual acuity in both eyes.

\section{CORTICAL BLINDNESS}

One child was 'cortically blind'. Born at 26 weeks she had had a particularly difficult neonatal period. Following an intraventricular haemorrhage she developed hydrocephalus, which was treated by a ventriculo-peritoneal shunt. Subsequently she developed at least two episodes of meningitis and blockage of the shunt. When examined she had severe spastic quadriplegia, entire developmental delay, mild myopia and bilateral optic atrophy. It was extremely difficult to quantify the degree of visual impairment attributable to optic nerve disease and that related to the postchiasmal pathways.

Five children had mild to moderate impairment of visual acuity in one or both eyes unassociated with any abnormality of the media fundus or error of refraction and may have had minor cortical visual impairment.

\section{MYOPIA}

Five of $49(10 \%)$ children were myopic (range -1.50 to $-8.00 \mathrm{D}$ ) (Figure 1). In only one was the vision correctable to $6 / 6$ in each eye., Three had reduced vision due to anisometropia and squint and one had both optic atrophy and cortical blindness. Two children had family history of myopia in close relatives. A family history in two other children was unavailable because they had been adopted. Three of the five myopic children were found to have straightening of the temporal vascular arcades but no other stigmata of ROP. They had not been ventilated for longer than 24 hours and all weighed over $900 \mathrm{~g}$.

\section{Discussion}

This study has been largely concerned with the detection of anatomical and functional defects of the visual system in a group of ELBW babies delivered to residents of a geographically defined area. The high incidence of ocular morbidity of $59 \%$ could have been due to bias in the sample, because children with known or obvious defects were more likely to be available for ophthalmic examination. The group of children not seen did not differ from those who were seen in mean birth weight or mean gestational age (Table 4). Neither did the proportion of children with an 


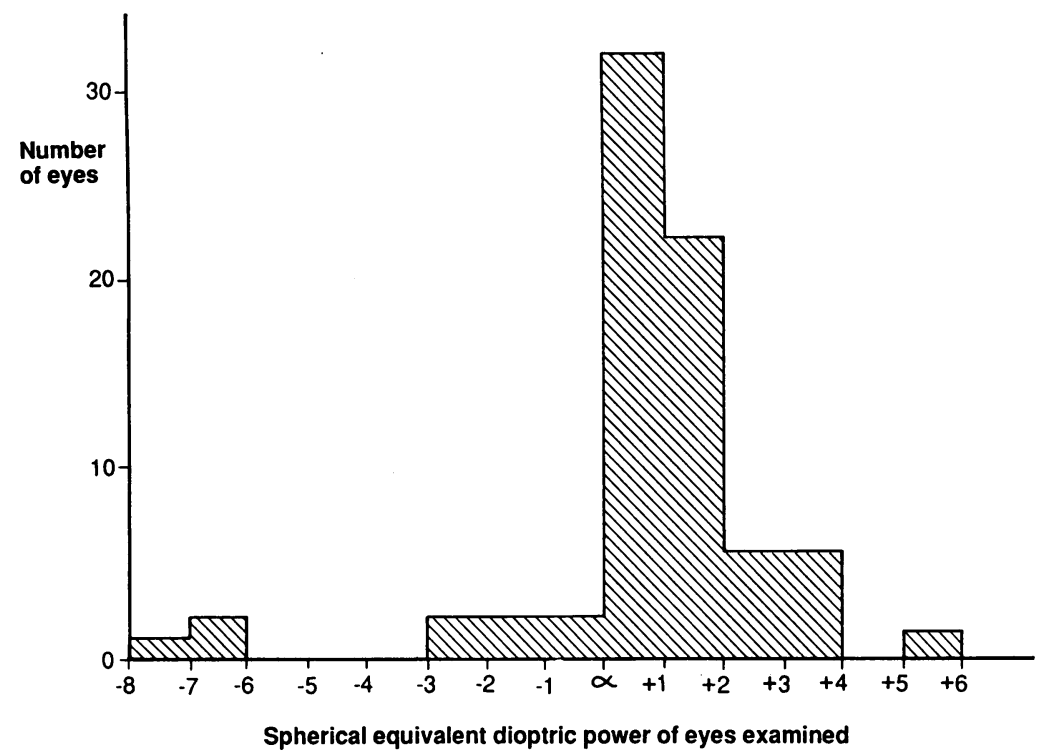

Figure 1 Refractive data.
Table 4 Birth weight, gestational age, and impairment code of all survivors to 4 years

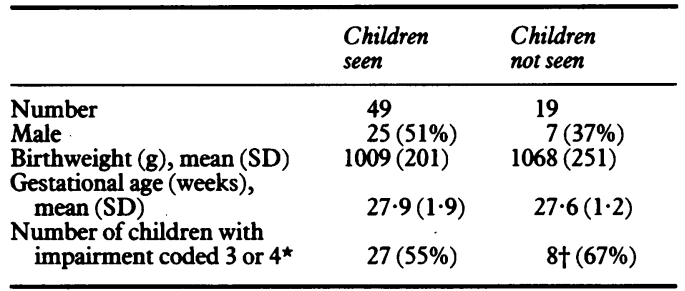

^Impairment code $3=$ impairment in one or more areas resulting in mild to moderate disability. Impairment code 4 includes cerebral palsy, severe sensory loss, total developmental delay. t Impairment codes not available for seven infants (unavailable for assessment because overseas, etc.)

babies without ROP, and $5 \%$ in a comparable group of full term babies. Anisometropia inducing strabismus and amblyopia only partly explains these findings. The incidence of strabismus in this study (24\%) is higher than in similar studies, where incidences of $12 \%$ and $19 \%$ have been noted. One explanation for this is the older population seen in the Oxford study, with an increased risk of accommodative esotropia and consecutive divergence.

In this study one-third of the squints were divergent, a much higher proportion than that seen elsewhere in similar but not strictly comparable groups and again may be due to the age of the population examined. In Black's study ${ }^{15}$ of visual disorders associated with cerebral palsy he also noted a convergence:divergence ratio of 2:3:1.

The strong association between myopia and convergent squint has also been noted by Keith and Kitchen ${ }^{11}$ and Kushner ${ }^{13}$; the mechanism is presumably a type of sensory deprivation esotropia. The incidence of squint is higher in children with neurological deficit, especially cerebral palsy. ${ }^{15}$ The mechanism for this is not fully explained, but children with the spastic type of cerebral palsy are the most likely to have ocular defects. In them the pathology is extensive and diffuse, with periventricular and subcortical haemorrhage and cortical atrophy. $1.5 \mathrm{~kg}$ ranges from $1.8 \%$ to $4 \%,{ }^{589}$ but the distribution is markedly skewed towards those weighing less than $1 \mathrm{~kg}$. Cicatricial disease occurs in $22-42 \%$ of these smallest survivors, ${ }^{289}$ whereas $5-11 \%$ of them are blind. $\mathrm{Ng}$ et $\mathrm{al}^{13}$ in a geographically defined study in Britain confirmed the greater severity of ROP with shorter gestation and lower birth weight. The early and frequent examinations of babies in their study identified a very high incidence of acute ROP. The incidence of cicatricial disease was low, and they suggest that this may be partly due to racial factors. The incidence of cicatricial disease in our study may be underestimated owing to the difficulties of examining the peripheral fundus of children of this age. Indeed three of the myopic children had straightening of the temporal vascular arcades and probably had ROP. If these children are included, the incidence of cicatricial ROP was $5 / 49$ or $10 \%$.

\section{STRABISMUS}

The incidence of strabismus is higher in preterm than full term babies. Kushner, ${ }^{14}$ for example, found an incidence of $34 \%$ in a group of babies with regressed ROP, $16 \%$ in a group of preterm

\section{OPTIC NERVE ABNORMALITIES}

The association between cerebral palsy and ocular morbidity is well recognised. ${ }^{16} 17$ The $4 \%$ incidence of optic atrophy in this study compares with reported incidences of $2 \%{ }^{10}$ and $3 \% .^{11}$ Possible mechanisms for optic atrophy are that it is secondary to hydrocephalus and also is associated with cerebral palsy. ${ }^{\text {is }}$ In the same study hypoplastic discs were seen in $3 / 120(2 \cdot 5 \%)$ children with severe spastic cerebral palsy; our child with hypoplastic discs also had severe spastic cerebral palsy. There were two cases of relatively innocuous disc abnormalities (one tilted disc and buried drusen) which have not previously been recorded as a feature of low birth weight.

CORTICAL BLINDNESS

Diffuse cortical deficit may be associated with visual impairment without any abnormality of the eyes or anterior visual pathways. ${ }^{18}$ The acuity in these children is usually limited to counting 
fingers or less. Colour vision and the ability to perceive movement is better than form perception. There is a broad spectrum of disability in this condition. It has recently become apparent that visual acuity in children who were born prematurely is less good than in full term controls. This seems to be the result of some other factor associated with prematurity. ${ }^{1920}$ It may be that the five children in our study with decreased acuity without any ophthalmic explanation have the latter type of cortical visual impairment.

\section{MYOPIA}

There is a well recognised relationship between myopia and ROP..$^{21-24}$ Myopia has been described as a feature of all grades of ROP but occurring in up to $80 \%$ of patients with cicatricial disease. ${ }^{25}$ Asymmetrical myopia can result in severe anisometropic amblyopia in an eye with only minimal cicatricial changes. Several studies have reported that the myopia is not solely due to increased axial length but may have lenticular and corneal components. ${ }^{26-28}$

Because of the high incidence of ocular morbidity in ELBW babies it is recommended that such children should not only be examined by an ophthalmologist in the nursery to detect ROP but also followed up during early childhood to detect, and if possible treat, any associated ocular disorder. Some of these children have multiple handicaps, and visual defects may be overlooked, with serious visual and educational implications. Babies of extremely low birth weight contribute minimally to the total ocular pathology seen in early childhood. However, the risk of abnormality is high, and they warrant thorough ophthalmic assessment and care.

The authors thank Mr J J Kanski and Dr Andrew Wilkinson for their help in the preparation of this paper. Action Research for the Crippled Child funded the neurodevelopmental part of the study.

1 Saigal S, Rosenbaum P, Hattersley B, Milner R. Decreased disability rate among three year old survivors weighing 500 $1000 \mathrm{~g}$ at birth. $\mathcal{F}$ Pediatr $1989 ; 114: 839-46$.

2 Cooke RWI. Referral to a regional centre improves outcome in extremely low birthweight infants. Arch Dis Child 1987; 62 : 619-21.

3 Aylward GP, Pfeiffer SI, Wright A, Verhulst SJ. Outcome studies of low birth weight infants published in the last decade: A meta-analysis. F Pediatr 1989; 115: 515-20.

4 Patz A. Retrolental fibroplasia. Surv Ophthalmol 1969; 14 $1-29$.

5 Gunn TR, Easdown J, Outerbridge EW, Aranda JV. Risk factors in retrolental fibroplasia. Pediatrics 1980; 65: 1096 100.

6 Hammer ME, Mullen PW, Ferguson JG, et al. Logistic analysis of risk factors in acute retinopathy of prematurity. Am F Ophthalmol 1986; 102: 1-6.

7 Bauer CR. The occurrence of retrolental fibroplasia in infants of birth weight 1000 grams and less. Clin Res 1978; 26: 824A

8 McCormick AQ. Retinopathy of prematurity. Curr Probl Pediatr 1977; 7: 11 .

9 Shahinian L, Malachowski N. Retrolental fibroplasia. A new analysis of risk factors based on recent cases. Arch Ophthalmol 1978; 96: 70-4

10 Saigal S, Rosenbaum P, Stoskopf B, Sinclair JC. Outcome in infants 501 to $1000 \mathrm{gm}$ birth weight delivered to residents of the McMaster Health Region. F Pediatr 1984; 105: 969-76.

11 Keith CG, Kitchen WH. Ocular morbidity in infants of very low birth weight. Br $\mathcal{F}$ Ophthalmol 1983; 67: 302-5.

12 Hungerford J, Stewart A, Hope P. Ocular sequelae of preterm birth and their relation to ultrasound evidence of cerebra damage. Br 7 Ophthalmol 1986; 70: 463-8.

$13 \mathrm{Ng}$ YK, Fielder AR, Shaw DE, Levene MI. Epidemiology of retinopathy of prematurity. Lancet 1988; ii: 1235-8.

14 Kushner BJ. Strabismus and amblyopia associated with regressed retinopathy of prematurity. Arch Ophthalmol 1982; 100: 256-61.

15 Black P. Visual disorders associated with cerebral palsy. $\mathrm{Br} \mathcal{F}$ Ophthalmol 1982; 66: 46-52.

16 Breakey AS. Ocular findings in cerebral palsy. Arch Ophthalmol 1955; 53: 852-6.

17 Smith VH. Strabismus in cerebral palsy. Br Orthopt $\mathcal{f} 1965$ 22: 84-94.

18 Jan JE, Groenveld M, Sykanda AM, Hoyt CS. Behavioura characteristics of children with permanent cortical visua impairment. Dev Med Child Neurol 1987; 29: 571-6.

19 Fledelius HC. Ophthalmic changes from age of 10 to 18 years. A longitudinal study of sequels to low birth weight. II Visual acuity. Acta Ophthalmol $(K b h) 1981$; 59: 64-70.

20 Sebris SL, Dobson V, Hartman EE. Assessment and prediction of visual acuity in 3 to 4 -year-old children born prior to term. of visual acuity in 3 to 4-year-old

21 King MJ. Retrolental fibroplasia: a clinical study of two hundred and thirty-eight cases. Arch Ophthalmol 1950; 43 694-711.

22 Reese AB, Stepanik J. Cicatrical stage of retrolental fibroplasia Am f Ophthalmol 1954; 38: 308-16.

23 Birge HL. Myopia caused by prematurity. Trans Am Ophthalmol Soc 1955; 53: 219-30.

24 Fletcher MC, Brandon S. Myopia of prematurity. Am $f$ Ophthalmol 1955; 40; 474-81.

25 Tasman W. Late complications of retrolental fibroplasia. Ophthalmology 1979; 86: $1724-40$.

26 Majima A. Studies on retinopathy of prematurity II. Fundus appearance and ocular functions in cicatricial phase of very appearance and ocular functions in cicatricial phase of very

27 Hibino Y, Takahashi M, Majima A. Studies on ocular functions of cicatricial retinopathy of prematurity. Measurement of refractive elements. $\mathcal{F}$ pn $\mathcal{F}$ Clin Ophthalmol 1978; 32 655-62.

28 Gordon RA, Donzis PB. Myopia associated with retinopathy of prematurity. Ophthalmology 1986: 93: 1593-8. 